\title{
Maturation of Responsiveness to Cardioactive Drugs
}

\author{
DIFFERENTIAL EFFECTS OF ACETYLCHOLINE, \\ NOREPINEPHRINE, THEOPHYLLINE, TYRAMINE, \\ GLUCAGON, AND DIBUTYRYL CYCLIC AMP ON \\ ATRIAL RATE IN HEARTS OF FETAL MICE
}

\author{
Kern Wildenthal with the technical assistance of Jacquline R. Wakeland \\ From the Pauline and Adolph Weinberger Laboratory for Cardiopulmonary \\ Research, Departments of Physiology and Internal Medicine, The University \\ of Texas Southwestern Medical School at Dallas, Dallas, Texas 75235
}

A в S T R A C T Freshly isolated hearts of fetal mice of gestational ages ranging between 12 and 22 days (term) were exposed to several concentrations of a variety of chronotropic agents. Acetylcholine $\left(10^{-4}-10^{-2} \mathrm{M}\right)$ caused marked bradycardia in all hearts, even after only 12-14 days' gestation (i.e., even before cardiac innervation had occurred), and the intensity of the response increased steadily with advancing age throughout gestation. Responsiveness to norepinephrine was present but minimal at $12-14$ days, so that mean atrial rate rose by $<10 \%$ with a maximal concentration of the drug $\left(10^{-5} \mathrm{M}\right)$; responsiveness became more marked by 15-16 days (just after the time atrial innervation is thought to begin) and still greater effects appeared just before term. Glucagon had no effect in hearts of $<17$ days' gestational age, but caused tachycardia thereafter, indicating that cardiac responsiveness to glucagon differentiates later than does responsiveness to norepinephrine. Responses to theophylline in 12-14 day hearts exceeded those to norepinephrine, indicating that the drug can affect heart rate independently of its ability to cause release of endogenous catecholamines. In contrast, tyramine caused no response until 21-22 days, well after the time the beta-receptor has differentiated and after innervation is fairly well developed, suggesting that the drug's primary sympathomimetic effect is indirect rather than direct. Dibutyryl cyclic AMP did not cause tachycardia at any fetal age.

Received for publication 27 February 1973 and in revised form 27 April 1973.
It is concluded that maturation of responsiveness of the mouse heart to cardioactive drugs develops in specific patterns for different agents. The identification of differential patterns of maturation for various drugs may provide valuable means for characterizing the differentiation of specific receptors and for investigating possible mechanisms of action of the drugs.

\section{INTRODUCTION}

As the immature heart develops it acquires the ability to be influenced by a variety of cardioactive agents. Cardiac responsiveness to many of these agents, notably the physiological neurotransmitters, has often been noted to be different in fetuses than in the adult animals (1-3). The time-course of the maturation of responsiveness throughout late fetal development has not been well defined, however. Accordingly, to determine the pattern of responsiveness to a variety of chronotropic agents during cardiac development, experiments were made to quantify the atrial rate response in hearts of fetal mice of gestational ages ranging between 12 and 22 days (term). To avoid the confusing influences of secondary changes in heart rate mediated by alterations in neural and humoral factors, the experiments were made on freshly isolated hearts under stable, controlled conditions in vitro.

Special attention was directed toward defining specific response patterns to different drugs and thus to identifying stages of myocardial differentiation when cells are 
reactive to some drugs but have not yet acquired the ability to respond to others. Recognition of such situations not only has intrinsic descriptive interest but also provides avenues for exploring mechanisms of actions of the drugs.

\section{METHODS}

Intact hearts were carefully dissected from fetal mice of known gestational ages and transferred to small, specially constructed chambers for subsequent experimentation. In the chambers, the hearts lay on stainless steel grids and were bathed from beneath by a nutritive solution that was composed of medium 199 (Grand Island Biological Co., Grand Island, N. Y.), $50 \mu \mathrm{g} / \mathrm{ml}$ of purified bovine insulin (Schwartz/Mann Div., Becton, Dickinson \& Co., Orangeburg, N. Y.), and $\mathrm{NaHCO}_{3}$ in an amount to maintain a $\mathrm{pH}$ of 7.4, while their upper surfaces protruded into the atmosphere to facilitate gas exchange. Each isolated heart was allowed to stabilize in a $95 \%$ oxygen atmosphere in a $37^{\circ}$ incubator for $2-3 \mathrm{~h}$ before experiments were begun. The chamber was then transferred to a $37^{\circ}$ water bath in room air where, over a period of 5-10 min, a doseresponse curve to the drug being evaluated was obtained. Previous studies have established that fetal mouse hearts prepared in the manner described beat in control media at a constant rate and with a constant amplitude of contraction for over $20 \mathrm{~min}$ or more after the chamber has been transferred to the water bath (4), so the duration of each experiment in the present study was well within the period of stability of the system.

Dose-response curves relating spontaneous heart rate to the concentration of the drug being evaluated were obtained for 330 hearts by procedures described in a previous publication (5). Briefly, the medium was replaced with fresh control medium and the control atrial rate was counted through a dissecting microscope after a $30-45$ s stabilization period. The control medium was then replaced at $1 \mathrm{~min}$ intervals by identical media supplemented with progressively increasing doses of the drug. Atrial rates were counted at each level after stabilization. A new steady-state maximal rate was achieved by $30-45 \mathrm{~s}$ following application of the various cardiotonic agents, after which the rate was counted over a $30 \mathrm{~s}$ period. Following application of acetylcholine, on the other hand, a new steady state was usually not achieved until after $60 \mathrm{~s}$, and the rate stabilized then at a level that was often higher than the minimal rate observed during the first few seconds. Because of its greater reproducibility, the steady-state rate, rather than the minimal one was analyzed in the present study. As can be appreciated from previous studies (6), the minimal effective dose of acetylcholine might appear to be smaller than that reported in this study if transient changes rather than steadystate conditions are analyzed.

For each counting period both the absolute beating rate and the rhythm were noted. At no age and with no drug did premature or irregular contractions occur in more than $10 \%$ of the hearts tested, and neither atrial fibrillation nor paroxysmal tachycardia (i.e., a rapid, regular rate that appeared abruptly rather than gradually) was ever observed; absolute rates in those hearts that did develop arrhythmias were similar in all instances to others in their groups and mean values were not changed significantly by inclusion of the hearts with beating irregularities in the total calculations.
The following drugs were tested: $l$-norepinephrine-bitartrate, $10^{-8}-10^{-5} \mathrm{M}$ (Winthrop Laboratories, New York); acetylcholine- $\mathrm{HCl}, 10^{7-}-10^{-2} \mathrm{M}$ (Sigma Chemical Co., St. Louis, Mo.); tyramine $\mathrm{HCl}, 10^{-6}-10^{-3} \mathrm{M}$ (Sigma); theophylline, $10^{-6}-10^{-2} \mathrm{M}$ (Calbiochem, Los Angeles, Calif.); glucagon, $10^{-7}-10^{-5} \mathrm{M}$ (Sigma); dibutyryl, cyclic, $-3^{\prime}-5^{\prime}-$ adenosine monophosphate (dibutyryl cyclic AMP), $10^{-6}-$ $10^{-2} \mathrm{M}$ (Calbiochem); and $l$-isoproterenol $\mathrm{HCl}, 10^{-8}-10^{-5} \mathrm{M}$ (Winthrop). The concentrations used were determined in preliminary experiments to encompass the minimal and maximal responses that were seen at any age.

All mice used in the present study were of the Swiss albino strain and were bred in our institution. Gestational ages of the fetuses were timed from a 1 day period of exposure of the female to a male. The recorded ages (accurate to $\pm 12 \mathrm{~h}$ ) thus refer to the time from insemination rather than from implantation. Normal term in our strain at the time of the experiments averaged $21 \frac{1}{2}$ days with $>90 \%$ pregnancies lasting $20 \frac{1}{2}-22$ days; rarely, deliveries

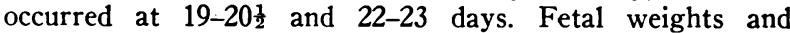
crown-to-rump lengths in the present experiments correlated well with published tables that relate size to gestational age in other strains $(7,8)$. Also, cardiac weights were closely grouped at each separate age tested so that cardiac and total body size in each age displayed negligible overlap with other ages. Average blotted, wet weights of isolated hearts in the age ranges tested were: $0.9 \mathrm{mg}$ (1314 days), $1.6 \mathrm{mg}$ (15-16 days), $2.7 \mathrm{mg}$ (17-18 days), 4.6 $\mathrm{mg}$ (19-20 days), and $8.5 \mathrm{mg}$ (21-22 days).

Statistical analyses of the data obtained in the experiments were made with Student's $t$ test. Each drug was tested on a minimum of 10 hearts of each age. Analyses of the significance of the drug-induced changes at each concentration for a given age group were made by the test for paired observations, with each heart's baseline rate as its own control. Comparisons between age groups were made by the test for grouped data. Results were similar when comparisons were made on the basis of absolute changes from baseline rates or of percentage changes. Values for grouped data have been expressed throughout the paper as the mean \pm 1 standard error of the mean.

\section{RESULTS}

Baseline atrial rates in vitro were similar at each of the ages studied. The average rate for hearts of 13-14-day fetuses was $157 \pm 3.9$ beats $/ \mathrm{min}$; hearts of 15-16-day fetuses beat at a rate of $150 \pm 4.5 ; 17-18$-day hearts, $148 \pm$ $4.4 ; 19-20$ days, $157 \pm 6.4$; and $21-22$ days, $160 \pm 7.2$.

Initial studies were directed at defining the response patterns to the normal neurotransmitters, acetylcholine, and norepinephrine. All hearts responded to acetylcholine by developing bradycardia. As shown in Fig. 1, the response of 13-14-day hearts was significantly less marked than at older ages, and the response increased in magnitude progressively until term. Thus, an acetylcholine concentration of $10^{-3} \mathrm{M}$ caused a decrease in atrial rate of $28 \pm 10.4 \%$ at $13-14$ days, $53 \pm 14 \%$ at 15 16 days, $67 \pm 8.6 \%$ at $17-18$ days, and $85 \pm 10.5 \%$ at 19 20 days. At the same concentration, hearts from fetuses near term (21-22 days) consistently developed atrial standstill. Responses at one or more dose levels changed 


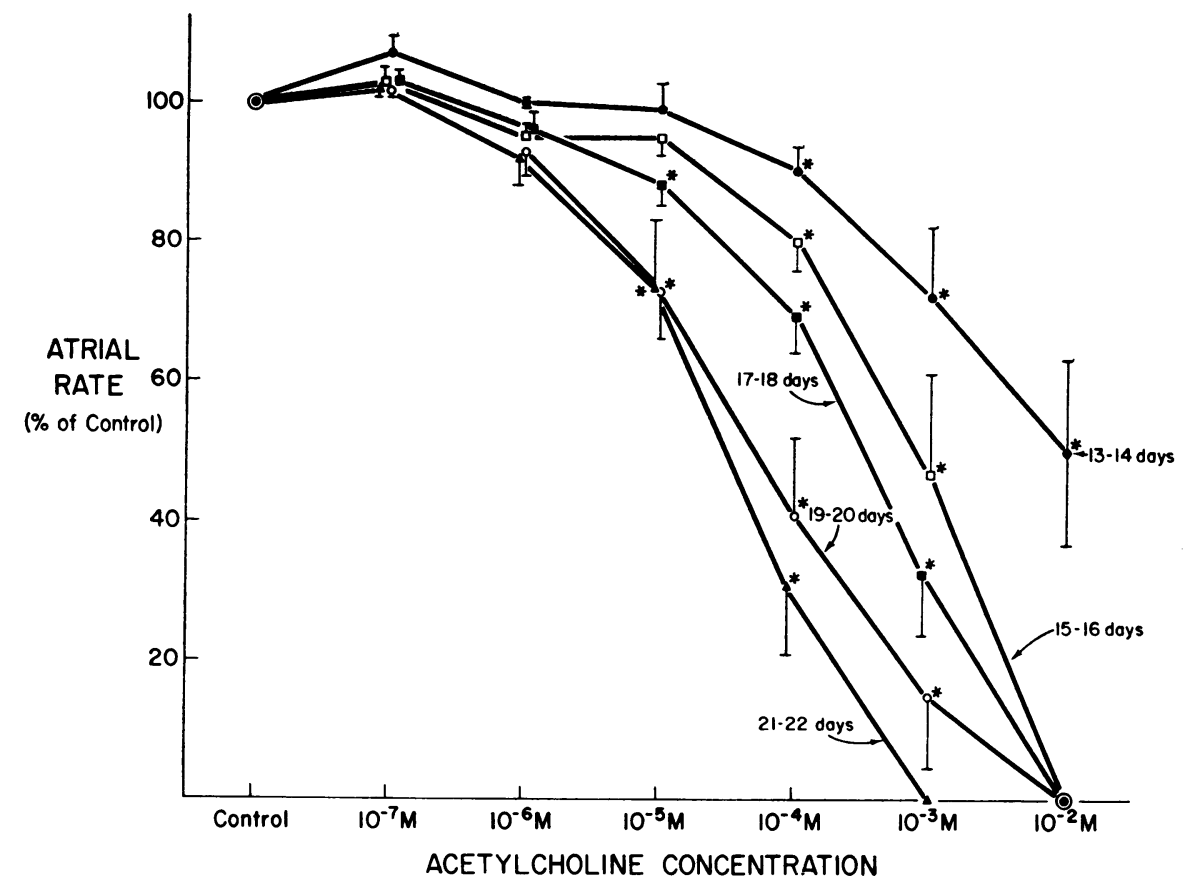

FIGURE 1 Influence of acetylcholine on spontaneous atrial rate at various fetal ages. Each group comprised 10-14 hearts. Rates at each concentration are expressed as a percentage of the control rate. The vertical bars represent \pm 1 standard error of the mean. Asterisks signify statistically significant changes from the control rates for each group.

significantly $(P<0.05)$ between $13-14$ and $15-16$ days and between 17-18 and 19-20 days.

The response pattern to norepinephrine was different from that to acetylcholine in several particulars (Fig.

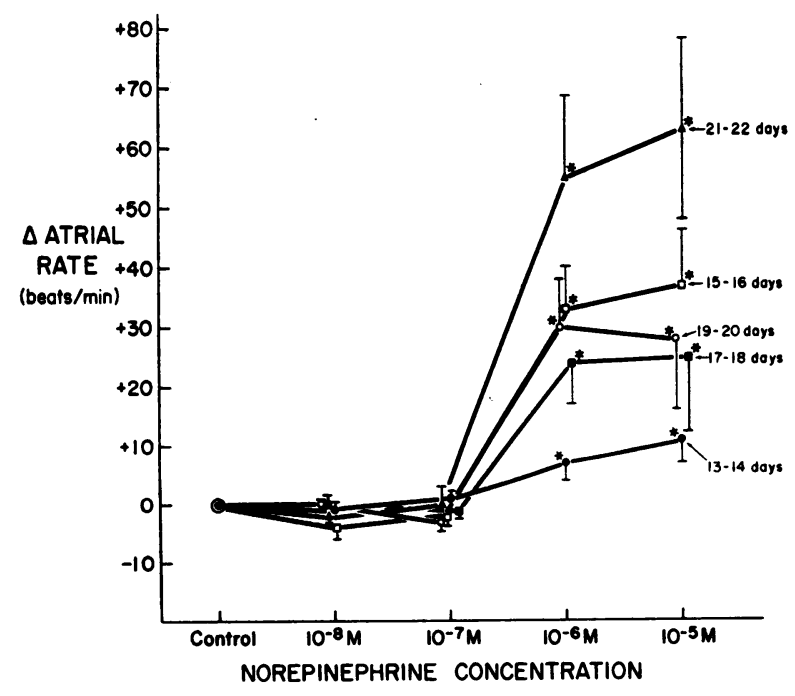

Figure 2 Influence of $l$-norepinephrine on spontaneous atrial rate at various fetal ages. The atrial rates at each concentration are expressed as absolute changes from the control rate. Symbols and conditions are identical to those in Fig. 1.
2). Most noticeably, responses in hearts of 13-14 day fetuses were less consistent and less marked to the sympathetic agent. $39 \%$ of the hearts failed to increase their rate at all at any concentration of the drug, and the average maximal increase, although statistically significant, was only $11 \pm 4.0$ beats $/ \mathrm{min}$ or $8 \%$ above baseline levels. The progression of maturation was also somewhat different for norepinephrine responsiveness. A dramatic increase in responsiveness appeared by $15-16$ days; then, no further change appeared until just before term when an additional increase in the tachycardia produced by the drug was noted. Thus, the increases in rate induced by $10^{-8} \mathrm{M}$ norepinephrine were $7 \pm 3.0$ beats/min in 13-14-day hearts, $33 \pm 7.4$ at 15-16 days, $24 \pm 7.2$ at $17-18$ days, $30 \pm 8.3$ at $19-20$ days, and 55 \pm 13.7 at $21-22$ days.

The results obtained with norepinephrine suggested that both the cardiac beta-receptor and the entire intracellular machinery that translates beta-receptor stimulation into an increase in spontaneous beating rate have become sufficiently developed in most hearts to influence heart rate significantly at some time before 15-16 days' gestation. To confirm this view, and to rule out any idiosyncracies in the fetal mouse heart's response to norepinephrine in comparison to other sympathomimetic agents, the effects of isoproterenol were evaluated in an identical manner in a small number of hearts (five to 


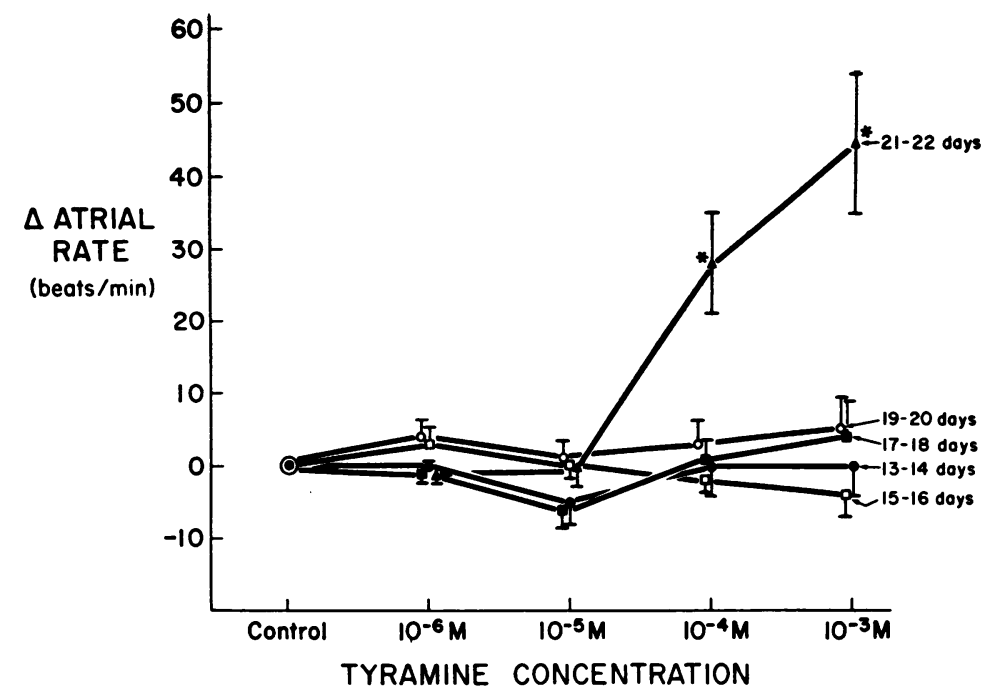

FIgURE 3 Influence of tyramine on spontaneous atrial rate at various fetal ages. Symbols and conditions are identical to those in Fig. 2.

seven in each age group). The results obtained with this agent, which also stimulates the beta receptor directly but which is normally inactivated by somewhat different pathways, were similar qualitatively and quantitatively to those obtained with norepinephrine. Thus, in the presence of $10^{-8} \mathrm{M}$ isoproterenol, atrial rate rose above baseline levels by $10 \pm 9.6$ beats $/ \mathrm{min}(P<0.10)$ at 13-14 days, $30 \pm 8.4(P<0.05)$ at $15-16$ days, 24 $\pm 4.3(P<0.01)$ at $17-18$ days, $30 \pm 7.4(P<0.05)$ at 19-20 days, and $48 \pm 11.5(P<0.05)$ at $21-22$ days.

The sympathomimetic agent tyramine has generally been believed to act primarily in an indirect manner, by releasing endogenous stores of norepinephrine, which in turn would stimulate beta receptors (9). Some recent work has suggested, however, that a direct stimulation of the beta receptor by tyramine itself is responsible to a major degree for the tachycardia it induces $(10,11)$. If the latter view is correct, it might be expected that the maturation of responsiveness to tyramine would mirror that to norepinephrine and isoproterenol. On the other hand, if tyramine acts only indirectly, one would expect that it would have no effect on heart rate until the heart has accumulated significant stores of norepinephrine, which does not occur until relatively late in gestation, well after the time cardiac innervation has begun $(12,13)$. Experiments in the isolated fetal mouse heart revealed that tyramine had no significant effect until 21-22 days' gestational age, just before birth and considerably later than the time the beta receptor has already differentiated (Fig. 3). At that age, the concentration of the drug required to increase the heart rate was $10^{-4} \mathrm{M}$ and maximal effects were achieved at $10^{-3} \mathrm{M}$.
In contrast, theophylline, which is also believed to act in part indirectly by inducing release of endogenous norepinephrine $(14,15)$, already caused significant tachycardia by 13-14 days' gestation (Fig. 4), confirming that the agent has a direct chronotropic effect as well as an indirect action and suggesting that the receptor that mediates the effect differentiates as early as or even earlier than the beta-receptor. As fetal development proceeded, responsiveness to theophylline increased in an irregular pattern similar to that of norepinephrine. Thus, statistically significant differences in responses to theophylline $(P<0.05)$ occurred between 13-14-day and 15-16-day hearts and between those of 19-20-day and 21-22-day gestational ages. At each age the tachycardia induced by theophylline was the greatest observed for any of the drugs, and the change induced in 21-22-day hearts $(+103$ beats/min at the maximal dose) was the maximum observed under any circumstances.

The response pattern to glucagon was different from all the other agents that were tested (Fig. 5). The drug had no effect in hearts of 13-16 days' gestational age. In 17-18-day hearts it caused minimal but statistically significant tachycardia at concentrations of $10^{-8}$ and $10^{-5} \mathrm{M}$. Much greater effects were seen in 19-22-day hearts, and at those ages significant responses occurred with doses as small as $10^{-7} \mathrm{M}$.

To see if the time-course of the development of responsiveness to any of the chronotropic agents could be correlated with responsiveness to exogenously administered cyclic AMP the dibutyryl derivative of that agent, which enters myocardial cells more readily, was given in concentrations of $10^{-6}-10^{-2} \mathrm{M}$. At no age did 


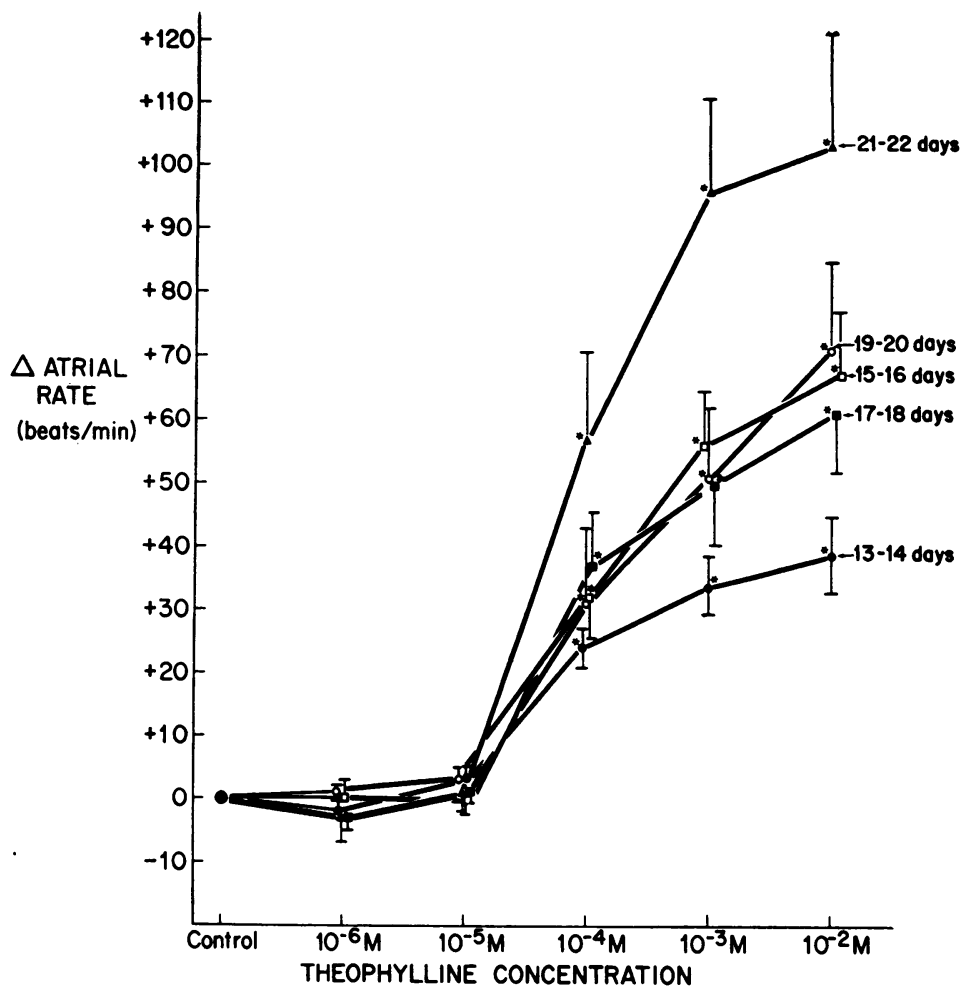

Figure 4 Influence of theophylline on spontaneous atrial rate at various fetal ages. Symbols and conditions are identical to those in Fig. 2.

tachycardia ensue following any dose, and a few hearts even developed bradycardia responses to the highest concentration of the drug. Because dibutyryl cyclic AMP's effect in isolated cardiac muscle can be slow in onset, observations in 19-22-day hearts were extended in 16 experiments over $30 \mathrm{~min}$ in the presence of a 3 $\times 10^{-3} \mathrm{M}$ concentration of the agent with an atmosphere

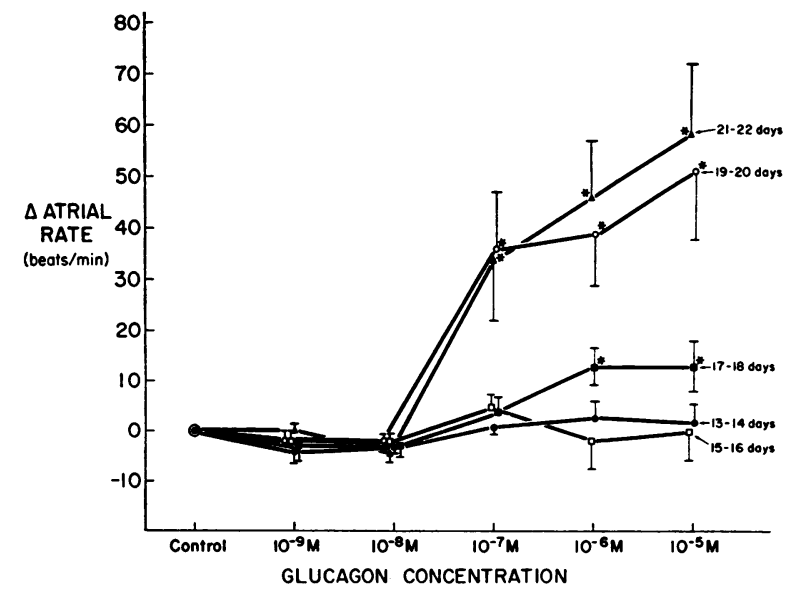

FigURE 5 Influence of glucagon on spontaneous atrial rate at various fetal ages. Symbols and conditions are identical to those in Fig. 2. of $95 \%$ O. The mean change in heart rate after 30 min was $-10 \pm 4.9$ beats $/ \mathrm{min}$. After the final rates were counted the hearts were assayed for glycogen by the method of Lowry, Passonneau, Hasselberger, and Schulz (16) ; levels were 23\% lower in hearts exposed to dibutyryl cyclic AMP than in litter-matched hearts exposed to control medium in an identical fashion (74 $\pm 7.7 \mu \mathrm{mol}$ glucose $/ \mathrm{g}$ vs. $96 \pm 6.6, P<0.01)$, suggesting that the absence of a chronotropic effect was not due simply to a failure of the agent to penetrate the cells.

Finally, the effects of all of the drugs were tested in hearts of fetuses aged 12 days or less. At those ages many of the tiny hearts $(<0.7 \mathrm{mg}$ weight $)$ failed to beat regularly and stably in vitro, so that meaningful quantification of rate changes was impossible in many instances. However, directional changes following exposure to maximal concentrations of the agents could be monitored, and it was found that the young hearts responded qualitatively in a manner resembling the response in 13-14-day hearts. Thus, acetylcholine consistently caused slowing of the rate, theophylline caused tachycardia, and tyramine and glucagon had no effect. Norepinephrine and isoproterenol caused either no change or, in 6 of 10 trials, a slight rise in the rates of the 12-day hearts. 


\section{DISCUSSION}

It is well recognized that fetal hearts do not always respond to cardioactive agents in the same way as adult hearts (1-3). Differentiation of specific receptor sites and full maturation of the cellular mechanisms that mediate changes in beating in response to a given agent often lag behind the development of rhythmicity and the ability of the fetal heart to contract. The present experiments provide for the first time a comparative survey of the time-course of maturation of responsiveness to a variety of agents throughout late fetal development in a single species. It should be emphasized that differences in the net responses observed could represent not only differences in the degree of differentiation of receptors but also differences in drug transport or metabolism; similarly, the formation, breakdown, or final effect of any second messengers that might be involved in mediating a drug's actions could change with maturation. Thus, the net responses observed in the present experiments represent the maturation of several integrated factors that may be important in determining the final chronotropic effect of an agent at a given age. It is also apparent that maximal responsiveness at a given age might conceivably be limited by the intrinsic ability of the heart to alter its rate, independent of the agent that initiates the change. In the context of the present study, this factor might be applicable to theophylline (the maximally effective agent at all ages), but not to the other chronotropic drugs tested.

Several other points relevant to interpretation and extrapolation of these data deserve mention. First, the present results were obtained under controlled, artificial conditions in vitro. Thus, the responses demonstrated should not be assumed to be identical to physiological responses in vivo, where a variety of secondary factors may play an important role $(2,17)$. Rather, the responses represent the intrinsic capabilities of the atria under one set of defined circumstances. Second, it should be noted that although fetal maturation may proceed in a similar manner in many mammalian species, major differences in various species may occur as well. Thus, results from mice cannot necessarily be extrapolated to other species. Third, although development of atrial and ventricular responsiveness in an animal might be expected to be similar in general, some discrepancies might occur, especially since ventricular innervation lags behind atrial by a few days $(12,18)$. Last, it should also be mentioned that chronotropic and inotropic responsiveness, though often appearing in concert with each other, might not necessarily develop in an identical manner.

Viewed in this context, the results of these experiments emphasize that the response of the heart to a drug may vary widely during fetal life, even after the initial differentiation of the specific receptor and appearance of responsiveness have occurred. Thus, unmodified descriptions of "fetal responsiveness" to a drug may in some instances be incomplete and potentially misleading. Responses often change dramatically over a brief period; the effects of an agent just before term, for example, may be quite different from the changes induced by the same drug a few days earlier. In addition, the results demonstrate that the ability to respond to different cardioactive agents often appears at different stages of maturation.

Analyses of the patterns of maturation of responses to the neurotransmitters acetylcholine and norepinephrine would be especially meaningful if they could be correlated with knowledge of the development of cardiac innervation. Because of the difficulty in timing the initiation of gestation exactly and because interindividual differences may be fairly large even in the same litter (7), comparisons of the present experiments with previous anatomical studies that made use of different breeding stock must be made cautiously and confined to rather broad time scales (i.e, days rather than hours). With that limitation in mind, available evidence for correlating fetal size and age with development of nerves in the mouse $(7,18)$ suggests that cardiac innervation does not begin until after the 12th or 13th day of a $21+$ day gestation period. Sympathetic and parasympathetic fibers probably begin to penetrate the atria around days 14-15 in most instances. By 15-16 days innervation of the atria should have occurred in all hearts, and as gestation proceeds there is a continued and progressive increase in the number of nerve fibers that are present in the atrial tissue. In general, accumulation of norepinephrine in sympathetic nerve endings lags behind the anatomical appearance of the nerves in the heart (12); although complete data are lacking in the mouse, it seems likely from studies of other species that significant stores of endogenous norepinephrine do not begin to appear until just before birth $(12,13)$.

Viewed in conjunction with these anatomical data, the results of the present study indicate that the ability of the mouse heart to respond to acetylcholine precedes cardiac innervation. Average changes suggest that responsiveness to sympathetic amines is also present in preinnervated hearts, but responses to those agents are small and inconsistent in hearts of less than 15 days' gestational age. Thus, although differentiation of the beta receptor and/or internal response mechanisms to beta stimulators apparently has begun before innervation, it remains poorly developed until around the time the nerves begin to come in contact with myocardial cells. These data from mouse hearts are reminiscent of 
some previous studies of other species. Hall (3), who studied hearts of fetal rats before innervation, observed that they responded appropriately to acetylcholine and epinephrine and that acetylcholine responsiveness was quantitatively more marked. Similar preinnervation responsiveness has also been documented in hearts of chick embryos $(19,20)$, but results in fish suggest that at least some animals are dependent upon prior innervation for neurotransmitter responsiveness to be present (21).

After innervation, the patterns of maturation of responsiveness to the neurotransmitters continue to display minor but noticeable differences. Responses to equimolar concentrations of acetylcholine increase fairly steadily with age. On the other hand, responses to norepinephrine change in a less regular manner; between 15 and 20 days' gestational age there is no apparent alteration in the extent to which a given dose of the drug increases the beating rate, but in the few hours preceding term there is a dramatic increase in responsiveness. At all fetal ages, the chronotropic effect of isoproterenol is qualitatively and quantitatively similar to that of norepinephrine, as has been noted for their inotropic effects in other species (1).

In addition to being of intrinsic interest, knowledge of the specific patterns of maturation of responsiveness to a given agent may open new avenues for exploring its mechanisms of action. For example, identification of disparities in the development of responsiveness to different agents could provide strong evidence that their modes of action are partially different. If responsiveness to a sympathomimetic agent develops before cardiac innervation has occurred, the agent can be assumed to act at least in part through direct effects on the heart; on the other hand, a sympathomimetic agent that cannot alter the heart beat until well after innervation could be assumed to act primarily indirectly, through releasing endogenous norepinephrine from nerve endings.

In this regard, the present experiments provide further substantiation for the view that the ability of tyramine to increase heart rate is mediated primarily through indirect actions. The inability of the drug to increase the heart rate at 15-20 days' gestational age. when the beta receptor is already well differentiated, and the appearance of tyramine responsiveness just before term at a time when endogenous stores of norepinephrine are accumulating are compatible with a purely indirect mechanism of action. It should be mentioned, however, that one cannot rule out absolutely the possibility that the properties of the beta receptors might change with time so as to make the receptor able to respond to compounds with a slightly different molecular structure than was possible in earlier stages of fetal development; such changes in receptor properties have never been documented, however, and it seems unlikely that such a phenomenon would account for the present results.

In contrast, theophylline, which also is known to act in part by causing release of endogenous norepinephrine $(14,15)$, clearly is able to cause significant tachycardia at 12-14 days, when responsiveness to norepinephrine is minimal. Therefore, it must have other, direct actions on fetal heart rate. Complete interpretation of the significance of the early reactivity to theophylline is made difficult by the present lack of full information on the drug's various mechanisms of action. In adult hearts it is known to inhibit the enzyme phosphodiesterase and thereby increase intracellular levels of cyclic AMP, and that action has been proposed as the means by which changes in beating are mediated (22). If that hypothesis is correct, the present data suggest that the ability of the heart to respond to increased intracellular levels of cyclic AMP is fairly well developed by the time the beta receptor differentiates fully. However, because the methyl-xanthine phosphodiesterase inhibitors have still other actions, as well, definitive conclusions on this point cannot yet be made. Comparison of theophylline's effects with those of nonmethyl-xanthine phosphodiesterase inhibitors during early fetal life will be especially interesting in clarifying this point.

Glucagon, like norepinephrine, acts on the heart to stimulate adenylate cyclase activity and to increase heart rate and contractility, but it does so by a mechanism that does not involve the beta receptor (23). The present results suggest that differentiation of the glucagon receptor and/or the other cellular processes that translate receptor stimulation into tachycardia occurs well after differentiation of the beta receptor and the other factors involved in mediating sympathetic effects. Experiments on hearts of lambs $(24,25)$ and rats $(26$. 27) have also suggested that cardiac responsiveness to glucagon is slow to appear, but normal glucagon responsiveness in those two species apparently does not develop until after birth. If the mouse heart is unique in its ability to increase its beating rate after exposure to glucagon before birth, it will be of special interst to test whether or not the mouse heart also displays significant activation of adenylate cyclase in response to glucagon during fetal life, unlike other animals. If it does not, that would constitute impressive evidence against a role for cyclic AMP in mediating glucagon's chronotropic effects.

Interest in elucidating the role of cyclic AMP in controlling myocardial beating has led to numerous investigations of the effects of its dibutyryl derivative, which can penetrate cells more readily than the parent compound. Results have been quite variable, and species differences seem to be of major importance (28-31). 
Mouse hearts have not received as much attention as many other species in this regard, nor have chronotropic effects been evaluated as completely as inotropic effects; also, the influence of cardiac maturation has not been considered, as a rule. In the present experiments dibutyryl cyclic AMP appeared unable to increase the beating rate of fetal mouse hearts of any age. Because of the unphysiological nature of this intervention and in view of the widely discrepant results in many previous evaluations of the drug's effects, it seems impossible to draw any definitive conclusions from these or similar data about the physiological importance of cyclic AMP in controlling heart rate. Nevertheless, the results do provide yet another example of instances in which a disparity between cardiac dynamic and metabolic effects of exogenous cyclic AMP and its derivatives can be demonstrated (31-33).

\section{ACKNOWLEDGMENTS}

This work was supported in part by grants from the U. S. Public Health Service (HL 14706) and the American Heart Association, and by a U. S. Public Health Service Research Career Development Award (HL 70125).

Dr. Jan Karlsson kindly provided the glycogen assays.

\section{REFERENCES}

1. Friedman, W. F. 1972. The intrinsic physiologic properties of the developing heart. Prog. Cardiovasc. Dis. 15: 87.

2. Adolph, E. F. 1971 Ontogeny of heart-rate controls in hamster, rat, and guinea pig. Am. J. Physiol. 220: 1896.

3. Hall, E. K. 1957. Acetylcholine and epinephrine effects on the embryonic rat heart. J. Cell Comp. Physiol. 49: 187.

4. Wildenthal, K., D. R. Harrison, G. H. Templeton, and W: C. Reardon. 1973. Method for measuring the contractions of small hearts in organ culture. Cardiovasc. Res. 7: 139.

5. Wildenthal, K. 1972. Studies of isolated fetal mouse hearts in organ culture: evidence for a direct effect of triiodothyronine in enhancing cardiac responsiveness to norepinephrine. J. Clin. Invest. 51: 2702.

6. Wildenthal, K. 1971. Responses to cardioactive drugs of fetal mouse hearts maintained in organ culture. Am. J. Physiol. 221: 238.

7. MacDonald, E. C., C. G. MacDowell, and E. Allen. 1927. The prenatal growth of the mouse. J. Gen. Physiol. 11: 57 .

8. Otis, E. M., and R. Brent. 1954. Equivalent ages in mouse and human embryos. Anat. Rec. 120: 33.

9. Shore, P. A. 1962. Release of serotonin and catecholamines by drugs. Pharmacol. Rev. 14: 531 .

10. Varma, D. R., and E. Ayitey-Smith. 1967. Effect of tyramine on the atrium and the papillary muscle of the immunosympathectomized rat. J. Pharm. Pharmacol. 19: 557.

11. Zaimis, E. 1968. Vasopressor drugs and catecholamines. Anesthesiology. 29: 732.

12. Friedman, W. F., P. E. Pool, D. Jacobowitz, S. C. Seagren, and E. Braunwald. 1968. Sympathetic inner- vation of the developing rabbit heart; biochemical and histochemical comparisons of fetal, neonatal, and adult myocardium. Circ. Res. 23: 25.

13. Mirkin, B. L. 1972. Ontogenesis of the adrenergic nervous system: functional and pharmacologic implications. Fed. Proc. $31: 65$.

14. Westfall, D. P., and W. W. Fleming. 1968. Sensitivity changes in the dog heart to norepinephrine, calcium, and aminophylline resulting from pretreatment with reserpine. J. Pharmacol. Exp. Ther. 159: 98.

15. Marcus, M. L., C. L. Skelton, L. E. Grauer, and S. E. Epstein. 1972. Effects of theophylline on myocardial mechanics. Am. J. Physiol. 222: 1361.

16. Lowry, O. H., J. V. Passonneau, F. X. Hasselberger, and D. W. Schulz. 1964. Effect of ischemia on known substrates and cofactors of the glycolytic pathway in brain. J. Biol. Chem. 239: 18.

17. Dawes, G. S., J. C. Mott, and B. R. Rennick. 1956. Some effects of adrenaline, noradrenaline and acetylcholine on the foetal circulation in the lamb. J. Physiol. (Lond.). 134: 139.

18. Tschernjachiwsky, A. 1928. Note sur le développement du système nervaux du coeur, la terminaison du nerf dépresseur et l'innervation du sinus carotidien. Trav. Lab. Rech. Biol. Univ. Madrid. 26: 75.

19. Markowitz, C. 1931. Response of explanted embryonic cardiac tissue to epinephrine and acetylcholine. Am. J. Physiol. $97: 271$.

20. Fingl, E., L. A. Woodbury, and H. H. Hecht. 1952. Effects of innervation and drugs upon direct membrane potentials of embryonic chick myocardium. J. Pharmacol. Exp. Ther. 104: 103.

21. Armstrong, P. B. 1935. The role of the nerves in the action of acetylcholine on the embryonic heart. $J$. Phy'siol. (Lond.). $84: 20$.

22. Sutherland, E. W., G. A. Robison, and R. W. Butcher. 1968. Some aspects of the biological role of adenosine 3'5'-monophosphate (cyclic AMP). Circulation. 37: 279.

23. Epstein, S. E., G. S. Levey, and C. L. Skelton. 1971. Adenyl cyclase and cyclic AMP: biochemical links in regulation of myocardial contractility. Circulation. 43: 437.

24. Downing, S. E., N. S. Talner, A. G. M. Campbell, K. H. Halloran, and H. B. Wax. 1969. Influence of sympathetic nerve stimulation on ventricular function in the newborn lamb. Circ. Res. 25 : 417.

25. Friedman, W., B. Sobel, and C. Cooper. 1969. The age dependent enhancement of cardiac contractility by glucagon: relationship to activation of the adenyl cyclase enzyme system. In Proceedings of the Society for Pediatric Research. 39: 20. (Abstr.)

26. Clark, C. M., Jr., B. Beatty, and D. O. Allen. 1973. Evidence for delayed development of the glucagon receptor of adenylate cyclase in the fetal and neonatal rat heart. J. Clin. Invest. 52: 1018.

27. Wildenthal, K., J. Karlsson, and J. R. Wakeland. 1973. Maturation of chronotropic, inotropic, and metabolic responsiveness to glucagon in hearts of fetal mice and rats. Fed. Proc. 32: 344A. (Abstr.)

28. Berti, F., V. Mandelli, and R. Paoletti. 1970. The effect of cyclic AMP on the heart rate of the isolated rat atria. Int. Z. Klin. Pharmakol. Ther. Toxikol. 4: 123.

29. Skelton, C. L., G. S. Levey, and S. E. Epstein. 1970. Positive inotropic effects of dibutyryl cyclic adenosine 3',5'-monophosphate. Circ. Res. 26: 35. 
30. Kukovetz, W. R., and G. Pöch. 1970. Cardiostimulatory effects of cyclic $3^{\prime}, 5^{\prime}$-adenosine monophosphate and its acylated derivatives. Arch. Pharmacol. Exp. Pathol. 266: 236.

31. Gartner, S. L., and G. V. Vahouny. 1972. Effects of epinephrine and cyclic $3^{\prime}, 5^{\prime}-\mathrm{AMP}$ on perfused rat hearts. Am. J. Physiol. 222 : 1121.
32. Langslet, A., and I. Øye. 1970. The role of cyclic $3^{\prime}, 5^{\prime}-$ AMP in the cardiac response to adrenaline. Eur. J. Pharmacol. 12 : 137.

33. Kjekshus, J. K., P. D. Henry, and B. E. Sobel. 1971. Activation of phosphorylase by cyclic AMP without augmentation of contractility in the perfused guinea pig heart. Circ. Res. 29: 468. 